\title{
Space and Creativity: Students' Opinions on School Space as a Component of the Creative Environment
}

\section{Marta Galewska-Kustra}

The Maria Grzegorzewska University, Poland

E-mail address: marta.galewska@gmail.com

ARTICLE INFO

Keywords:

Creative space

Creative physical environment

Creative school spaces

Creative school

Article history:

Received 15 December 2015

Received in revised form 24 March 2016

Accepted 26 March 2016

ISSN: 2354-0036

DOI: 10.1515/ctra-2016-0006
A B STRACT

Space understood as physical environment is the object of research in many fields, including social sciences. Previous studies point to the importance it may have for creative activity. School is one of the spaces where creative activity takes place. School is also supposed to support the development of students' creativity. The article presents research on school as a physical environment facilitating creativity. The main aim of the presented study was to identify the characteristics of schools that students evaluated as favourable and unfavourable to their creative activity. The following research questions were addressed: What features of school space are evaluated by students as favourable to their creative activity? What features of school space are evaluated by students as unfavourable to their creative activity? The research made it possible to identify the elements of school that students see as support for, or hindrance to, their creative activity.

\section{INTRODUCTION}

The physical environment is important for the development and functioning of the human being. Support for this thesis can be found in neuroscientific studies showing the impact of physical space on the construction and functioning of the brain. Research shows that neurogenesis is a process conditioned not only by biological factors, but also by external factors such as physical activity and the complexity of the external environment. Environmental enrichment has a positive impact on the structure and functioning of the brain (the amount of dendrites, the number of synapses) and on neurogenesis in the hippocampal area (e.g., Brown et al., 2003).

Space is also an object of interest in social sciences, including education studies, but it is certainly not a mainstream issue. However, it is worth noting that the physical environment where the learning process takes place has always been important 
in the thought of education reformers. It is enough to mention certain assumptions of educational philosophies of movements such as naturalism or progressivism to see how important the issue was for their representatives. For Jean-Jacques Rousseau, John Dewey or Ellen Key, the environment for upbringing and formal education was crucial. We are familiar with the descriptions of the difficulties faced by John Dewey (2010) in the search for school equipment that would make it possible to create an environment "for acting" rather than "for listening." The change that consists of placing the child at the centre of the learning process, deeming the child to be an active participant and instigator of his or her education, required a new environment, allowing and promoting personal activity. In the case of the Maria Montessori method, the design of the environment became one of the essential foundations of the entire educational system that was meant to create the possibility of achieving the essential aim: the independence of the child. Space is therefore considered by many educators, but is not a frequent subject of empirical, educational research.

The situation is similar in the case of creativity research. The importance of space and the material world in creativity is still quite rarely addressed, but the existing findings make it possible to identify the characteristics that facilitate or constrain the creative process. Dul, Ceylan, and Jaspers (2011) reviewed recent studies in this field and summarized the features of space that are relevant to creativity, such as: any view from the window, furniture, privacy, lighting, plants, physical indoor climate (humidity, temperature), sounds (positive: music, absence of noise, silence), odours (positive: fresh air, absence of bad smell). McCoy and Evans (2002) identified a view of the natural environment, sociopetal design, the presence of natural materials, the complexity of the space and the number of objects in the space as creative space characteristics, while lack of a view from the window, synthetic materials and colours, were considered to be elements unfavourable for creativity. Steidle and Werth (2013) suggested that dim light or even darkness may encourage creative thinking.

School is the place where a child spends most of the time during the day. If, therefore, school is treated as an important place in supporting the student's creative development, its space also becomes an interesting object of interest for creativity researchers.

Some researchers point to the physical environment of the school as one of the important environmental aspects of the student's creative activity (Davies, Jindal-Snape et al., 2013) and provide tips on the arrangement of that space to support creativity (Amabile, 1989; Paris, Edwards et al., 2006), but research rarely relates to school as the physical environment for students' creative activities. Davies, Jindal-Snape, Collier, Digby, Hayand Howe (2013), provide a critical analysis of selected empirical studies relat- 
ed to this issue (such as: Addison, Burgess, Steers, \& Trowell, 2010; Bancroft, Fawcett, \& Hay, 2008; Davies, 2011; Gandini, Hill, Cadwell, \& Schwall, 2005; Jeffrey, 2006). Their analysis leads them to recommend the following: a flexible working environment that adapts to the student's activity, the participation of parents and students in planning and equipping the class, the formation of large open spaces allowing free movement and activity depending on the student's needs. They also mention equipment as an essential element of the physical environment and recommend, for example, ensuring the availability and variety of resources and materials that can be used in different ways to support student's creativity.

Loi and Dillon (2006) also mention equipment. They treat the creative physical environment as part of continuous interaction with the student. Trying to build the concept of "adaptive educational environments as creative spaces," the authors point to objects that are strange and surprising and, when deliberately placed in space, can provoke or inspire creative action. Teresa Amabile (1989) describes supportive classroom space as visually stimulating, giving an opportunity for contact with various materials that inspire students to explore various areas of creativity, as well as for contact with creative products, including the effects of students' own creative activity. Other researchers give similar guidelines, describing a classroom that is conducive to creative activity, as surrounding the student with objects to explore and encouraging him or her to ask questions, and at the same time, full of materials (objects of everyday use, including ones brought by the students) that can be used to solve various problems (Paris, Edwards et al., 2006).

\section{METHOD}

\section{Participants}

Fifty students (aged 16 years; 31 women and 19 men) from a public high school in Łódź (the third largest city in Poland) took part in the study. The school was built in the 1980s, and its architecture is typical of Polish public schools, which were set up on a large scale during the Communist period. The school building is an example of socialist-realist architecture, whose purpose was to reflect the spirit of the socialist system. In spite of political and economic developments in Poland after 1989, the architecture of school buildings has remained largely unchanged. The vast majority of today's public school students study in buildings whose architecture is very similar to that of the school examined in this study.

\section{Procedure}

In the first part of the study, an instrument consisting of open-ended questions was used. It related to the presented problem situation (students solving problems creatively on the school premises). Students were asked, individually, to indicate the places at school 
where they would be most and least likely to go in a given situation: Imagine that you need to solve an unusual task at school. To solve it, it is not enough to give a short answer. It is also not enough to recall, for example, the date of some historical event. The task is a real problem to solve. It demands that you find a lot of unusual, creative solutions. You need to solve this problem at school, but you can choose any place within its premises, even a place where students do not usually go. Then the students justified their choices, answering the following questions: Why would you choose this particular place? What is there within its space that would help you solve the problem? Why wouldn't you go to this place? Why can't you imagine solving the problem there? Try to justify your choice. There was no time limit for completing the document. It usually took students around 40 minutes to complete it.

In the second part of the study, 24 students (six groups of four students) were asked to make any changes they wanted in the arrangement of the space presented in randomly chosen pictures (presented on B1 sheets). Some of the data obtained was used in the second stage of study: the images presented places that had been indicated in the first stage as the least conducive to the process of solving the creative problem. The idea of the creative project was to enrich the previously obtained data and confirm the proand anti-creative characteristics of the school listed by the students in the first part of the study. At this stage, an additional instrument consisting of open-ended questions was also administered and the freely offered opinions of the participants were collected, in which they justified their choice of solutions. Before starting to work on the task, each student received a sheet of paper with a description of a problematic situation - the same as in the first stage. This time, however, they were told that they would have to solve the problem in the place shown in the picture. The task was as follows: How would you change the place in order to make it more conducive to solving the problem and more helpful in the process of completing the task? Use your own ideas to try to design changes to the space presented. Remember - they are meant to be changes that, in your opinion, would improve the conditions for solving a particular task. During this stage, the students were allowed to use sheets of paper (B1 format), marker pens, glue, scissors, and numerous images showing interior equipment (they could choose any of these materials). At the end of the task, the students justified the changes they had applied in writing and verbally. The estimated time allowed for the task was $1.5 \mathrm{hrs}$., but all of the students managed to complete it somewhat sooner.

Written and verbal (transcribed) opinions as well as visual works (art works) were collected as the outcome of the study. The process of analysis included open and selective coding of the qualitative data (Gibbs, 2011). The aim of the analysis was to identify 
the main categories (characteristics of the school) emerging from the participants' evaluation of spaces with low and high perceived creativity potential.

\section{RESULTS}

\section{Pro-Creative Places at School and Their Characteristics in Students' Opinions}

In listing the places they would choose for solving the creative problem, students usually gave examples of selected classrooms or isolated spaces that gave them a sense of privacy and allowed them to focus (the library, unfrequented nooks such as quiet, unpopular ends of hallways and classrooms) as well as places that allowed free behaviour (a hallway functioning as a dining space, with small shops around it). It should be stressed that, in this case, the students often selected classrooms, but these indications related to only a few classrooms out of the large quantity of those available at this school. The reason for this is the factor that determined the choice of classroom: a teacher who was liked. Only classrooms associated with a popular teacher were mentioned at this stage of research. The characteristics that determined the choice of a particular space (in order of the frequency of student's indications) were as follows:

1. The presence of people who could help in the problem solving process. In particular:

- $\quad$ the presence of a popular, friendly teacher (the vast majority of justifications): "I would go there because teachers teaching in this classrooms create an amazing atmosphere."; "I can count on the teacher's support there."; "I would choose the history classroom because the history teacher has a good sense of humour and likes to work with students, and his classes are interesting. I have positive associations with this place."; "I feel comfortable there, I am not ashamed to ask questions."; "I feel very good there, teachers are very close to us there, we can talk about everything with them.";

- the presence of colleagues, who could possibly provide inspiration during problem solving: "I would choose the hallway because many of my friends are there during the breaks, and they would probably help me with some good ideas."

2. The physical features of the place. In particular:

- $\quad$ silence, peacefulness, privacy and isolation (the second most frequently mentioned feature): "I would choose this place because this hallway is peaceful and you can focus."; "This place is not very comfortable, but it is peaceful with not too many people around. So you can do the task in peace."; 'There are fewer people around and it's quieter than other places at school."

3. The furnishings/equipment of the place: equipment allowing free behaviour, relaxation (for example, drinking and eating while working); the availability of seats; access to the Internet and a computer: "The equipment here is suitable for the creative process." 
4. General, not clearly specified features of the place, determining its positive evaluation, described as:

- A sense of leisure and relaxation: "The hallway is a nice place. You can easily sit there, there is no chaos, sometimes they play some music there."; "That place is cozy, you can unwind there.";

- a general good mood: "I simply like it, there is a good atmosphere there."

\section{Anti-Creative Places at School and Their Characteristics in Students' Opinion}

Asked about places where they would not go in order to solve creative tasks, the students most often pointed to particular classrooms and places that did not give a sense of privacy and the possibility to focus (extremely crowded school hallways, the main hall of the school). The features that determined the negative evaluation of particular places were as follows (in order of the frequencyof students' indications):

1. The presence of negatively evaluated people are associated with the place, in particular:

- $\quad$ the presence of an unpopular teacher who teaches in a particular classroom: "I don't feel comfortable there. I don't like the classes taught by those teachers, and that is why I don't like those places."

2. The physical features of the place, such as: noise, crowdedness, poor light, humidity, lack of fresh air, uncomfortable temperature, unpleasant smells (cigarettes, toilets, food).

The art projects completed by the students provided another opportunity for them to specify the features of pro-creative places. The elements that were changed or removed from the spaces presented in the pictures also partly confirmed the data relating to anticreative places, obtained in Stage 1.

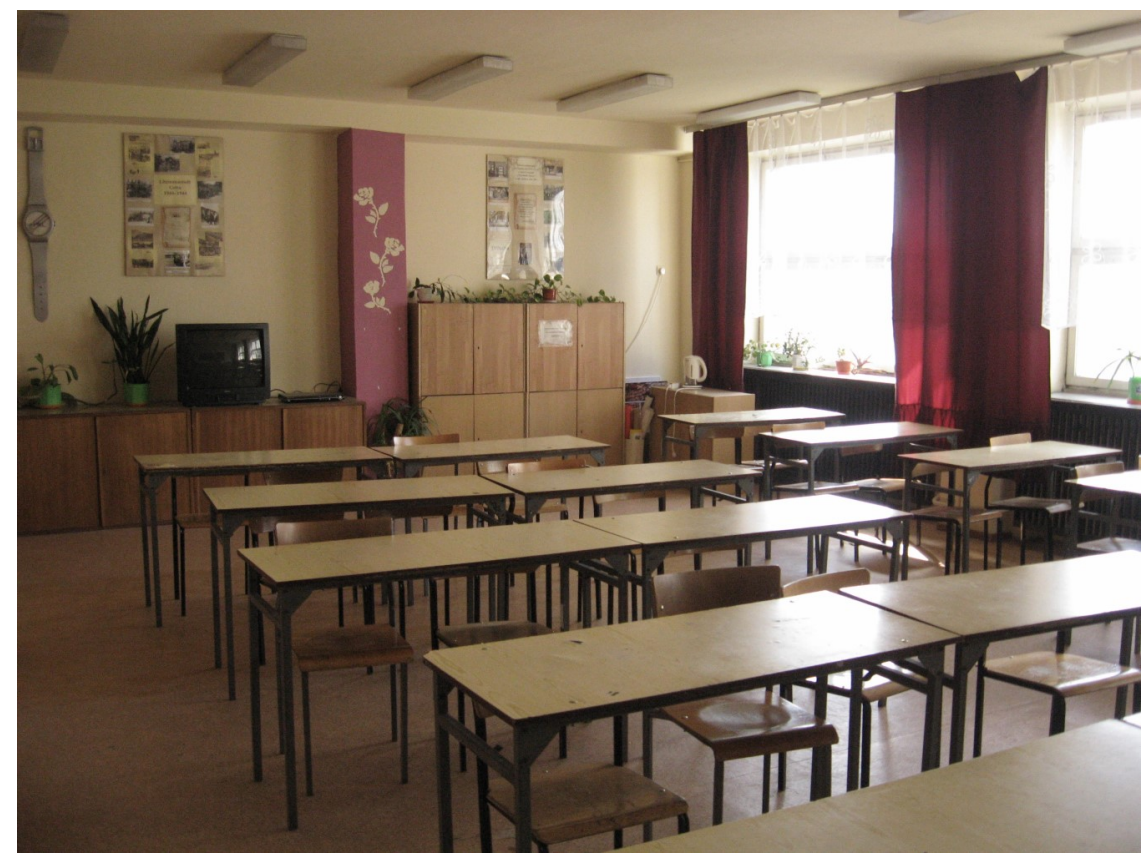

Figure 1 Negative people makes negative places:

I don't like the classes taught by those teachers, that is why I don't like those places. 
In the case of classrooms, the first and most frequent element that was changed was the teacher. The students justified this as follows: "The worst thing about this classroom is the presence of the teacher who creates a stressful atmosphere. He insults students, is arrogant, and doesn't possess knowledge of the subject that he teaches. The students predicted that bringing about a change in the teacher would leave them in a better mental state. A new teacher would help and support us"; "I don't like the teacher in this classroom. He constantly uses ready answers for the tests and the Internet. That's why nobody likes him. (...) in our project we have included a new teacher." Once again the teacher was the most important factor in the students' perceptions of school space.

Other changes made by the students related to the following groups of features:

1. Equipment that would influence the general positive atmosphere of the place, including:

- $\quad$ elements making the atmosphere of the place less formal and more homely: a small kitchen, a fridge, a kettle, a table with food, sofas, armchairs, a fireplace, pets (a dog), a change of wall colours to more "inspiring,"'warm," or"focus-supporting";

- $\quad$ equipment introducing an atmosphere of joy: a swing ("It was added because it is something that brings joy into life"); natural plants ("Natural, beautiful flowers always set up a good mood").

2. Elements of design influencing the physical parameters of the place: larger windows, better lights ("...so there is more air and light").

3. Elements providing comfort: armchairs, sofas, benches with soft pillows ("...for comfort and relaxation").

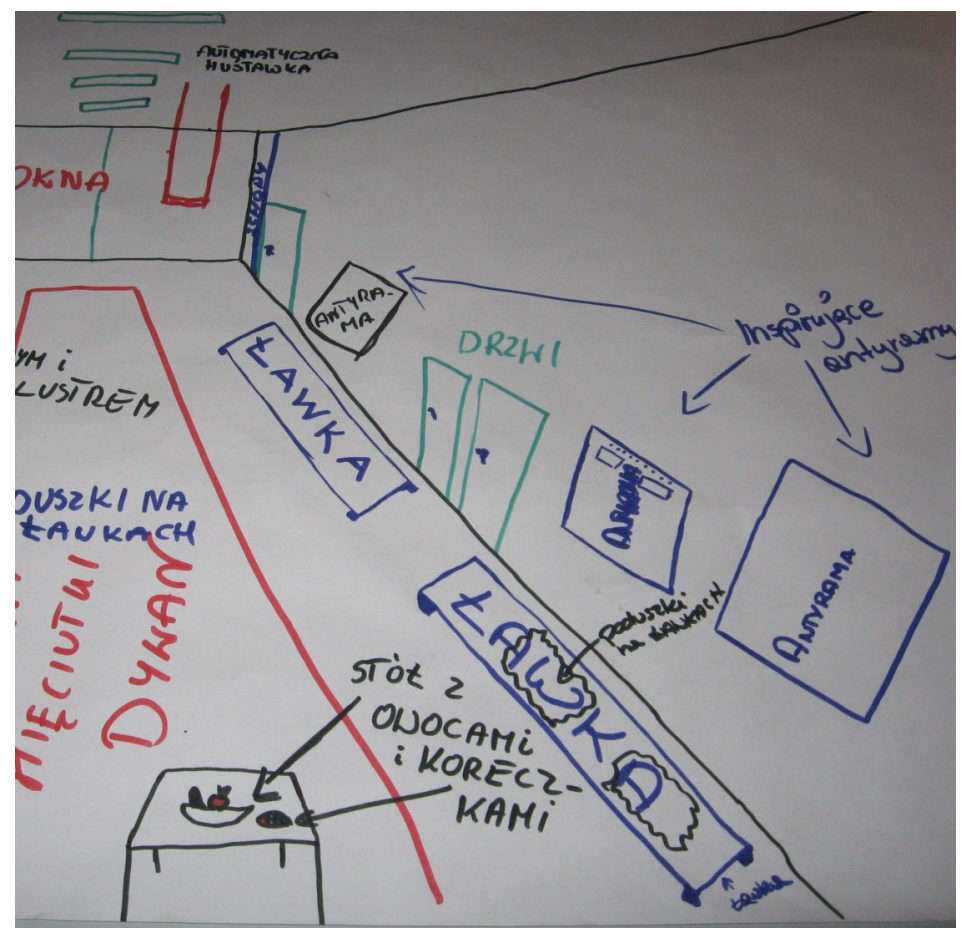

Figure 2 Changes of the anti-creative corridor: making the place more comfort, joyful and inspiring - benches with soft pillows, a table with food, a swing, inspiring posters. 
The second stage of the study confirmed the data obtained in the first stage. In the students' projects, the teacher associated with a given space became the first source of reflection and change. Further changes were focused on introducing elements that made the space less formal, more welcoming and more relaxing, as well as encouraging free behaviour.

\section{CONCLUSION}

\section{Negative people make negative (anti-creative) places, positive people make places positive (pro-creative) at school?}

In evaluating school space as a place of potential creative activity, students indicated features related to the physical atmosphere of the place that in their view, might promote or hinder the creative process. Places they considered to be potentially conducive to their creativity were quiet, peaceful and isolated. However, the most important element associated with any place was the teacher. As one of the participants wrote: The place is not important at all, it is all about the teacher. Choosing classrooms conducive to creative activity, students often mentioned a friendly teacher, who would help them to solve the problem. The teacher became even more important when students pointed to places they considered unfavourable to creativity. Places were dismissed by students if they were associated with an unpopular or hostile teacher. Other elements indicated earlier by creativity researchers (e.g., furniture, light, indoor physical climate) were also mentioned by the students, but it was the human factor that turned out to be the most important in the evaluation of places.

The presented study was an introduction to a broader research project on the impact of the school space on students'creative activity. Such research demands, among other things, a larger study sample. But the very need for such a sample already supports the first assumption, connected with the finding reported by Dul, Jaspers, and Ceylan (2011): space is important for creativity, but even more important is the social environment. In the case of school space, the social environment is decisive. Basically, this result only confirms that school is a place where social relationships and interactions between individuals are of special significance and play a crucial role. Based on students' answers, we can formulate a conclusion that requires further study: negative people make negative (anti-creative) places, while positive people make places positive (procreative).This conclusion, however, should not lead us to abandon considering space a significant element in school creativity. Further studies seem advisable; they should examine the relationship between space and the students' social environment. McCoy (2005) addressed these assumptions indicating the potential of space as a factor supporting creative teamwork. 
In the "pedagogy of place,"which has recently been developing in Poland, researchers highlight the importance of the space where education takes place. According to one of the Polish specialists in the field, creating this kind of place with pedagogical intention may itself be education (Mendel, 2006). The presented research was conducted in typical Polish school spaces, which need many changes. The awareness of this fact is more and more often an inspiration, not only for research, but also for attempts to introduce practical changes to the school environment in Poland. In the case of Polish education, a visible transition has been in progress in recent years: from research interest in the school space and the school building, including their symbolic significance (Nalaskowski, 2002; Nowotniak, 2006), to the implementation of practical projects that, by inspiring people involved in education, it is hoped, will bring about real changes to schools (for instance, the EDUSPACES21 project: http://www.eduspaces.eu/p/about.html).

School is one of the most important places for students' development and creative activity. Further research on the physical school environment could be an important aim for creativity researchers interested in educational practices that promote children's creativity. The physical environment should also be seen as an important factor in the general creativity environment. It demands attention in further research and should be taken into account in theoretical concepts of creativity (Glaveanu, 2013).

\section{REFERENCES}

Addison, N., Burgess, L., Steers, J., \&Trowell, J. (2010). Understanding art education: Engaging reflexively with practice. London: Routledge.

Amabile, T. M. (1989). Growing up creative. Nurturing a lifetime of creativity. Buffalo-New York: C.E.F. Press.

Bancroft, S., Fawcett, M., \& Hay, P. (2008). Researching children researching the world: $5 \times 5 \times 5=$ creativity. Trentham: Stoke-on-Trent.

Brown, J., Cooper-Kuhn, Ch. M., Kempermann, G., Van Praag, H., Winkler, J., Gage, F. H., \& Kuhn, H. G. (2003). Enriched environment and physical activity stimulate hippocampal but not olfactory bulb neurogenesis. European Journal of Neuroscience, 17, 2042-2046.

Center for Civic Education (CEO) (2016). EDUSPACES21. Retrieved March 21, 2016, from www.eduspaces.eu/p/about.html.

Davies, D., Jindal-Snape, D., Collier, C., Digby, R., Hay, P.,\& Howe, A. (2013). Creative learning environments in education:A systematic literature review. Thinking Skills and Creativity, 8, 80-91.

Dewey, J. (2010). School and society: Being three lectures. Eastford: Martino Fine Books. 
Dul, J., Ceylan, C., \& Jaspers, F. (2011). Knowledge workers' creativity and the role of the physical work environment. Human Resource Management, 50(6), 715. Retrieved. Gandini, L., Hill, L., Cadwell, L., \& Schwall, C. (Eds.). (2005). In the spirit of the studio: Learning from the atelier of Reggio Emilia. New York: Teachers' College Press.

Gibbs, G. (2007). Analyzing qualitative data.London, Los Angeles, New Delhi, Singapore, Washington D.C.: SAGE.

Glaveanu, V. P. (2013). Rewriting the language of creativity: The five A's framework. $R e-$ view of General Psychology, 17,69-81.

Jeffrey, B. (2006). Creative teaching and learning: Towards a common discourse and practice. Cambridge Journal of Education, 36(3), 399-414.

Loi, D., \& Dillon, P. (2006). Adaptive educational environments as creative spaces. Cambridge Journal of Education, 36(3), 363-381.

McCoy, J. M., \& Evans, G. W. (2002). The potential role of the physical environment in fostering creativity. Creativity Research Journal, 14(3\&4), 409-426.

McCoy, M. (2005). Linking the physical work environment to creative context. Journal of Creative Behavior, 39(3), 169-191.

Mendel, M. (Ed.) (2006). Pedagogika miejsca [The pedagogy of place]. Wrocław: DSWE TWP. Nalaskowski, A. (2002). Przestrzenie i miejsca szkoły [Spaces and places of school]. Kraków: Impuls.

Nowotniak, J. (2006). Kulturowy wymiar przestrzeni edukacyjnej: studium dwóch szkół. [Cultural aspects of educational space. A case study of two schools]. Szczecin: Print Group Daniel Krzanowski.

Paris, C., Edwards, N., Sheffield, E., Mutinsky, M., Olexa, T., Reilly, S., \& Baer, J. (2006). How early school experiences impact creativity. An ecological perspective. In J. C. Kaufman \& J. Baer (Eds.), Creativity and reason in cognitive development. Cambridge, New York, Melbourne, Madrid, Cape Town, Singapore, Sao Paulo: Cambridge University Press.

Steidle, A., \& Werth, L. (2013). Freedom from constraints: Darkness and dim illumination promote creativity. Journal of Environmental Psychology, 35, 67-80.

Corresponding author at: Marta Galewska-Kustra, Creative Education Lab, The Maria Grzegorzewska University, Szczesliwicka St., 40, 02-353 Warsaw, Poland E-mail: marta.galewska@gmail.com 